\title{
Color and translucency stability of CAD/CAM restorative materials
}

\author{
Rafaelo Fagundes Dalforno ${ }^{1}$ (D), Maria Luíza Auzani² (D), \\ Camila Pauleski Zucuni ${ }^{3}$ (D), Camila da Silva Rodrigues ${ }^{4 *}$ (D), \\ Liliana Gressler May ${ }^{3}$ (D)
}

${ }^{1}$ Graduate Program in Dental Sciences, Federal University of Santa Maria, Santa Maria, RS, Brazil

${ }^{2}$ School of Dentistry, Federal University of Santa Maria, Santa Maria, RS, Brazil

${ }^{3}$ Department of Restorative Dentistry, Federal University of Santa Maria, Santa Maria, RS, Brazil

${ }^{4}$ Department of Dental Materials and Prosthodontics, Institute of Science and Technology, São Paulo State University, São José dos Campos, SP, Brazil

\section{Corresponding author:}

Camila da Silva Rodrigues, DDS,

MS, PhD

Department of Dental Materials and Prosthodontics, Institute of Science and Technology, São Paulo State University

Address: Av. Eng. Francisco José Longo, 777, São José dos Campos, SP, Brazil, 12245-000

Phone: (55) 999474213

E-mail: camilasrdg@gmail.com

Editor: Altair A. Del Bel Cury

Received: February 25, 2021

Accepted: March 29, 2021
Aim: This study assessed the color and translucency stability of a polymer infiltrated ceramic network (PICN) and compared it with a resin composite (RC) and a feldspathic ceramic (FEL). Methods: Disc-shaped samples of a PICN (Vita Enamic), a feldspathic ceramic (Vitablocks Mark II), and a resin composite (Brava block) were prepared from CAD/CAM blocks. PICN and $\mathrm{RC}$ surfaces were finished with a sequence of polishing discs and diamond paste. FEL samples received a glaze layer. The samples were subjected to 30-min immersions in red wine twice a day for 30 days. CIEL $* a * b *$ coordinates were assessed with a spectrophotometer at baseline and after 15 and 30 days of immersion. Color alteration $\left(\triangle \mathrm{E}_{00}\right)$ and translucency parameter $\left(\mathrm{TP}_{00}\right)$ were calculated with CIEDE2000. Average roughness was measured before the staining procedures. Color difference and translucency data were analyzed with repeated-measures ANOVA and Tukey's tests. Roughness was analyzed with the Kruskal-Wallis test. Results: Roughness was similar among the experimental groups. All materials had their color alteration significantly increased from 15 to 30 days of staining. PICN reached an intermediate $\Delta \mathrm{E}_{00}$ between FEL and RC at 15 days. $\mathrm{PICN}$ revealed a color alteration as high as the composite after 30 days. No statistical difference was observed regarding translucency. Conclusion: PICN was not as color stable as the feldspathic ceramic at the end of the study. Its color alteration was comparable to the resin composite when exposed to red wine. However, the translucency of the tested materials was stable throughout the 30-day staining.

Key Words: Color. Ceramics. Composite resins. Computeraided design. Materials testing. Surface properties. 


\section{Introduction}

Computer-aided design and computer-aided manufacturing (CAD/CAM) technology has simplified the workflow for indirect restorations processing and enabled fabricating strong polycrystalline and glass-ceramics for dental applications. In addition to ceramics, resin composite blocks are industrially polymerized under standardized temperature and pressure parameters, which ensure their mechanical properties for CAD/CAM systems usage? .

Dental ceramics are generally stronger and more wear-resistant than resin composites $^{2,3}$. However, the brittleness of ceramics together with its susceptibility to slow crack growth ${ }^{4,5}$ might result in worse fatigue behavior compared to some composites $^{6}$. In an attempt to combine characteristics such as the resilience from resin composites and the resistance to abrasion from ceramics, a hybrid material was developed and made available as milling blocks. Vita Enamic (Vita Zahnfabrik) is a polymer-infiltrated ceramic-network (PICN) material which gathers a sintered feldspathic ceramic scaffold (86w\%) filled with a polymeric network $(14 \mathrm{w} \%)$ in a fully integrated structure. This combination results in a material with elastic modulus in the range of human dentin ( $30 \mathrm{GPa})$ and provides it with easy machinability. PICN can be milled more quickly than ceramics, which gives it a great advantage for chairside usage?

Ceramics are more esthetically stable than composites ${ }^{3,8,9}$. Resin composites are more susceptible to water sorption, mainly facilitated by hydrophilic compounds of its organic matrix ${ }^{10}$. Water sorption degrades the bonding between resin matrix and filler particles and pigments infiltrate easily in these interfaces ${ }^{11}$. In contrast, particle-filled glass-ceramics consists of a vitreous matrix filled with glass or crystalline particles ${ }^{12}$, which gives it a denser microstructure and results in less discoloration. PICN is expected to present an intermediate optical behavior between composite and ceramic. However, studies comparing the color and translucency stability of PICN with other CAD/CAM materials are required to confirm this information.

Studies have evaluated the color and/or translucency stability of PICN after days of immersion in staining beverages (e.g., coffee, tea, red wine, cola, or juice) and compared it with other restorative materials $s^{9,13-16}$. These studies applied diverse staining protocols and methods for calculating the optical properties, such as CIELAB ${ }^{9,14}$, CIEDE2000 ${ }^{13,15,16}$, translucency parameter ${ }^{13,14}$, percentage of light transmission ${ }^{9}$, or contrast ratio ${ }^{13,16}$. In addition, most of the studies perform silicon carbide paper polishing for all materials. The surfaces of the samples are finished on different grits (i.e. P4000, P1200) in each study, which might influence color stability and hinder the comparison of results. Composite, ceramics, and hybrid materials are clinically subjected to different finishing procedures prior to cementation. This should be considered for studying the optical behavior of restorative materials since it leads to more realistic results. Moreover, there is a need for studies using translucency and color calculation methods and clinical thresholds comparisons that are described in the literature as the most accurate ${ }^{17,18}$. 
Esthetic issues are one of the main cited reasons for substituting anterior composite restorations ${ }^{19}$ and feldspathic ceramic veneers ${ }^{20}$ in clinical follow-ups. As PICN is still a new material, there is little evidence from clinical studies ${ }^{21,22}$ and no consensus about its clinical behavior regarding esthetic issues. Furthermore, in vitro studies gives us an estimation of what to expect in vivo. Hence, this study aimed to assess the color and translucency stability of PICN and compare it with a resin composite $(\mathrm{RC})$ and a feldspathic ceramic (FEL) also available in CAD/CAM blocks. The tested hypotheses were that PICN would: 1) show intermediate color stability between the ceramic and the composite; and 2) its translucency would keep stable throughout the 30-day staining challenge.

\section{Materials and Methods}

\section{Study design}

The factors analyzed in this in vitro study were material (hybrid ceramic, feldspathic ceramic, or resin composite) and exposure time in the staining media (15 or 30 days). Measurements from the same sample were compared between the checkpoints (repeated measures approach). The outcomes studied were color difference $\left(\Delta E_{00}\right)$ and translucency $\left(\mathrm{TP}_{00}\right)$. The commercial brands, shades, and composition of the restorative materials used in this study are described in Table 1.

Table 1. Labels, material type, commercial brand, shades, and composition of each CAD/CAM material used in the study.

\begin{tabular}{ccccc}
\hline Label & Material & Commercial brand & Shade & Composition \\
\hline PICN & $\begin{array}{c}\text { Hybrid } \\
\text { Ceramic }\end{array}$ & $\begin{array}{c}\text { Vita Enamic } \\
\text { (Vita Zahnfabrik) }\end{array}$ & $1 \mathrm{M} 2 \mathrm{~T}$ & $\begin{array}{c}\mathrm{SiO}_{2}-\mathrm{Al}_{2} \mathrm{O}_{3}-\mathrm{Na}_{2} \mathrm{O}-\mathrm{K}_{2} \mathrm{O}-\mathrm{Br}_{2} \mathrm{O}_{3}-\mathrm{ZrO}_{2}-\mathrm{CaO}, \text { UDMA - } \\
\mathrm{TEGDMA}\end{array}$ \\
\hline $\mathrm{FEL}$ & $\begin{array}{c}\text { Feldspathic } \\
\text { Ceramic }\end{array}$ & $\begin{array}{c}\text { Vita Mark II } \\
\text { (Vita Zahnfabrik) }\end{array}$ & $\mathrm{A} 2 \mathrm{C}$ & $\mathrm{Al}_{2} \mathrm{O}_{3}-\mathrm{SiO}_{2}-\mathrm{Na}_{2} \mathrm{O}-\mathrm{K}_{2} \mathrm{O}$ \\
\hline $\mathrm{RC}$ & $\begin{array}{c}\text { Resin } \\
\text { composite }\end{array}$ & $\begin{array}{c}\text { Brava Block } \\
\text { (FGM Dental Group) }\end{array}$ & $\mathrm{A} 2 \mathrm{HT}$ & $\begin{array}{c}\text { Methacrylate monomers, initiator, co-initiator, } \\
\text { stabilizers, silane, glass-ceramic particles, } \\
\text { silica, and pigments. }\end{array}$ \\
\hline
\end{tabular}

\section{Sample preparation}

CAD/CAM blocks of a hybrid ceramic (PICN - Vita Enamic, Vita Zahnfabrik, Bad Sackingen, Germany), a feldspathic ceramic (FEL - Vita Mark II, Vita Zahnfabrik, Bad Sackingen, Germany), and a resin composite (RC - Brava block, FGM Dental Group, Joinville, Brazil) with initial dimensions of $12 \mathrm{~mm} \times 14 \mathrm{~mm} \times 18 \mathrm{~mm}$ were used to prepare disc-shaped samples $(10 \mathrm{~mm}$ diameter $\times 1.2 \mathrm{~mm}$ thick, $n=12)$. The blocks were ground into cylinders using a 100-grit SiC paper under water-cooling in a polishing machine (EcoMet 250, Buehler, Lake Bluff, USA). The cylinders were then sectioned into discs in a precision cutting machine (Isomet 1000, Buehler, Lake Bluff, USA) with a diamond blade. The PICN and RC discs had both sides ground with a 100-grit SiC paper to a thickness of $1.3 \mathrm{~mm}$. The FEL discs were ground until they were $1.2 \mathrm{~mm}$ thick. 
The top surface of PICN and RC samples were subjected to a sequence of coarse, medium, fine, and superfine polishing discs (Sof-Lex, 3M-ESPE, St. Paul, USA), and finished using a felt disc with aluminum-oxide extra fine $(6-8 \mu \mathrm{m}$ grit $)$ polishing paste (Diamond Flex and Diamond R, FGM Dental Group, Joinvile, Brasil). The polishing discs and felts were placed in parallel to the samples and the polishing was performed for 20 seconds for each disc. The samples were rinsed in water between discs. The polishing procedures were performed by a trained operator using a low-speed motor associated with a contra-angle handpiece ( 10,000 rpm) and light pressure. New polishing discs were used for each sample. The final thickness was $1.2 \mathrm{~mm}( \pm 0.05 \mathrm{~mm})$.

The FEL samples received a thin glaze layer on their top surfaces (Akzent Plus, VITA Zahnfabrik, Bad Sackingen, Germany). The glaze powder was mixed with the building liquid to obtain a creamy consistency. The mix was applied over the ceramic top surface with a brush, and the samples were subsequently fired in a furnace (Vacumat 600 MP, Vita Zahnfabrik, Bad Sackingen, Germany). Glaze firing was performed according to the manufacturer's instructions $\left(950^{\circ} \mathrm{C}, 1 \mathrm{~min}\right.$ dwell time). All the samples had their thickness measured with a digital caliper after the firing process. The thicknesses ranged from $1.23 \mathrm{~mm}$ to $1.27 \mathrm{~mm}$. The bottom surfaces (not glazed) of the ceramic samples were slightly ground with 100-grit SiC paper until $1.2 \mathrm{~mm}$ thick discs were obtained.

All samples $(n=12)$ were stored in distilled water at $37^{\circ} \mathrm{C}$ for $24 \mathrm{~h}$. Then, baseline $\mathrm{CIEL} * a * b *$ measurements were taken and the top surfaces of all samples had roughness measured to ensure standardization.

\section{Roughness measurements}

The roughness measurements were taken in a contact roughness tester (Mitutoyo SJ-410, Mitutoyo) according to the ISO Standard 4287-1997. The average roughness $(\mathrm{Ra})$ parameter of all samples was evaluated $(\mathrm{n}=12)$. Three measurements were obtained from the polished/glazed side of each sample in both the $X$ and $Y$-axis. A cut-off of IC $0.8 \mathrm{~mm}(\mathrm{n}=5)$ and a ripple filter of IS $2.5 \mathrm{~mm}$ was used. The mean Ra values of each sample were used in the statistical analysis.

\section{Staining procedures}

The samples were immersed in red wine (Salton Classic Cabernet Sauvignon, Vinícola Salton, Bento Gonçalves, Brazil) for 30 min at $37^{\circ} \mathrm{C}$ twice a day with a dwell time of $12 \mathrm{~h}$ between the immersions. This procedure was carried out for 30 days, totaling $30 \mathrm{~h}$ of immersion. After each immersion, the samples were rinsed and stored in distilled water at $37^{\circ} \mathrm{C}$ until the next immersion. The wine was replaced after every immersion. Red wine was chosen because it is acidic and rich in pigment, which has been demonstrated to result in high color alteration in ceramics, composites, and hybrid materials $\mathrm{s}^{9,14}$.

\section{Color and translucency stability analyses}

The CIEL*a*b*(Comission International L'Eclairage) parameters were assessed with a spectrophotometer (SP60, X-Rite, Grand Rapids, USA). The samples were placed 
over white, black, and gray backgrounds and the $L * a * b *$ parameters were recorded. The lightness axis $(L *)$ in this system ranges from 0 (black) to 100 (white), and a* and $b *$ are the color coordinates on green-red and in blue-yellow axes, respectively. The spectrophotometer was calibrated prior to the measurements. The assessments were carried out using a D65 light source (6500 K), observer angle of $10^{\circ}$, and specular component excluded (SPEX). A drop of a coupling agent with a refractive index of 1.47 was used (glycerol $\mathrm{C}_{3} \mathrm{H}_{8} \mathrm{O}_{3}$ ) to avoid the light dispersion between the sample and the background. Each sample was measured three times over each background and the average of these three measurements was used for color and translucency calculations. These measurements were taken at baseline and after 15 and 30 days of staining in red wine.

The values obtained over the gray background were used for color difference calculations with the CIEDE2000 formula (equation 1). The color alteration was calculated using the CIEL $* a * b *$ measurements at 15 and 30 days compared to the baseline $\mathrm{CIEL} * a * b *$ values (mutual comparison). The perceptibility $\left(\Delta \mathrm{E}_{00}>0.8\right)$ and unacceptability $\left(\Delta E_{00}>1.8\right)$ thresholds were considered for clinical inference ${ }^{17}$.

$\Delta E_{00}=\left[\left(\frac{\Delta L^{\prime}}{K_{L} S_{L}}\right)^{2}+\left(\frac{\Delta C^{\prime}}{K_{C} S_{C}}\right)^{2}+\left(\frac{\Delta H^{\prime}}{K_{H} S_{H}}\right)^{2}+R_{T}\left(\frac{\Delta C^{\prime}}{K_{C} S_{C}}\right)\left(\frac{\Delta H^{\prime}}{K_{H} S_{H}}\right)\right]^{\frac{1}{2}}$

where $\Delta L^{\prime}, \Delta C^{\prime}$, and $\Delta H^{\prime}$ are the differences in lightness, chroma, and hue, respectively, for a pair of measurements (baseline and 15 or 30 days of staining). The rotation function $R_{T}$ accounts for the interaction between chroma and hue differences in the blue region. Weighting functions $S_{L}, S_{H}$ and $S_{C}$ adjust the total color difference for variation in the location of the color difference pair in L', $a^{\prime}, b^{\prime}$ coordinates. The parametric factors $K_{L^{\prime}} K_{C^{\prime}}$ and $K_{H}$ are correction terms for deviation from reference experimental conditions. In this study, these parametric factors of the CIEDE2000 formula were set as 1 .

The translucency parameter $\left(\mathrm{TP}_{00}\right)$ was also calculated with the CIEDE2000 formula (equation 1). However, the pair of measurements used were the CIEL $* a * b *$ parameters obtained from each sample over the white and black backgrounds, separately for baseline, and after 15 and 30 days of staining.

\section{Statistical analysis}

The statistical analysis was carried out using the SigmaPlot 12.0 (Systat Software Inc, San Jose, USA) software program. Data were subjected to normality (Shapiro-Wilk test) and homoscedasticity (Levene test) tests. Next, average roughness data were analyzed with the Kruskal-Wallis test. Color difference data were analyzed with two-way repeated-measures ANOVA (material*staining time) and Tukey's test as post-hoc. Translucency stability was analyzed separately for each material using the one-way repeated measures ANOVA test. The CAD/CAM blocks chosen for this study are available in different color scales, so that translucency comparisons among materials would be biased. The significance level was set at $5 \%$. 


\section{Results}

Table 2 shows the roughness mean values for each material after the polishing procedures. No significant difference was observed in the Ra parameter among the experimental groups $(P>0.05)$. The statistical analysis regarding color stability (described in Table 3$)$ showed a significant effect from material $(P=0.002)$ and staining time $(P<0.001)$ on the studied outcome, as well as a significant interaction between these factors $(P=0.004)$. All three materials significantly increased their color alteration from 15 to 30 days of staining. PICN reached an intermediate color alteration between FEL and RC after 15 days. However, PICN revealed a color alteration as high as the resin composite after 30 days of staining, and the feldspathic ceramic was the most stable material. The restorative materials reached the color unacceptability threshold $\left(\Delta \mathrm{E}_{00}>1.8\right)$ after 15 days of staining. On the other hand, all three materials had their translucencies stable over the 30-day staining since no statistically significant differences were observed (Table 4).

Table 2. Means (standard deviations) of average roughness ( $\mathrm{Ra}$ ) of each experimental group after polishing procedures.

\begin{tabular}{cl}
\hline Materials & Ra $(\mu \mathrm{m})$ \\
\hline PICN & $0.36(0.08)^{\mathrm{a}}$ \\
\hline FEL & $0.36(0.22)^{\mathrm{a}}$ \\
\hline RC & $0.27(0.18)^{\mathrm{a}}$ \\
\hline
\end{tabular}

Different lowercase letter within a column indicates statistical differences among groups (Kruskal-Wallis test, $P<0.05)$

Table 3. Means (standard deviations) of color difference $\left(\Delta \mathrm{E}_{00}\right)$ of each material after 15 and 30 days of staining in red wine.

\begin{tabular}{lll}
\hline Materials & $\Delta \mathrm{E}_{00} 15$ days & $\Delta \mathrm{E}_{00} 30$ days \\
\hline PICN & $3.74(0.35)^{\mathrm{B}, \mathrm{ab}}$ & $4.95(0.80)^{\mathrm{A}, \mathrm{a}}$ \\
\hline FEL & $3.22(1.04)^{\mathrm{B}, \mathrm{b}}$ & $3.82(1.24)^{\mathrm{A}, \mathrm{b}}$ \\
\hline RC & $4.22(0.88)^{\mathrm{B}, \mathrm{a}}$ & $5.49(0.73)^{\mathrm{A}, \mathrm{a}}$
\end{tabular}

Different uppercase letter within a row indicates significant statistical differences between immersion times of the same material. Different lowercase letter within a column indicates statistical differences among materials in the same immersion time measurement (Two-way RM ANOVA, Tukey's test, $\mathrm{P}<0.05$ )

Table 4. Means (standard deviations) of translucency parameter $\left(\mathrm{TP}_{00}\right)$ of each material at baseline and after 15 and 30 days of staining in red wine.

\begin{tabular}{llll}
\hline Materials & $\mathrm{TP}_{\mathbf{0 0}}$ baseline & $\mathrm{TP}_{\mathbf{0 0}} \mathbf{1 5}$ days & $\mathrm{TP}_{\mathbf{0}} \mathbf{3 0}$ days \\
\hline $\mathrm{PICN}$ & $13.02(1.25)^{\mathrm{A}}$ & $13.52(1.34)^{\mathrm{A}}$ & $12.77(1.33)^{\mathrm{A}}$ \\
\hline $\mathrm{FEL}$ & $21.23(3.13)^{\mathrm{A}}$ & $21.11(1.40)^{\mathrm{A}}$ & $20.39(1.49)^{\mathrm{A}}$ \\
\hline $\mathrm{RC}$ & $24.44(3.35)^{\mathrm{A}}$ & $25.32(1.28)^{\mathrm{A}}$ & $23.34(1.16)^{\mathrm{A}}$
\end{tabular}

Distinct uppercase letter within a row indicates significant statistical differences among the immersion time measurements of the same material (One-way RM ANOVA, Tukey's test, $P<0.05$ ). 


\section{Discussion}

PICN exhibited the same color alteration as a machinable resin composite, which was less stable than a glass-ceramic after the total exposure time to red wine. However, its translucency was maintained throughout the 30 days of staining. This made the first and second tested hypotheses to be rejected and accepted, respectively.

All the materials reached the clinical unacceptability threshold at the first checkpoint (15 days). This observation was predictable since red wine has been described as the most pigmented beverage in in vitro studies ${ }^{9,15}$. The color stability of each material depends on the staining exposure time. PICN reached $\triangle \mathrm{E}_{00}$ values similar to both composite and ceramic after the first 15 days of exposure to red wine. In contrast, its color alteration was statistically similar to the composite and greater than the glass-ceramic after 30 days. PICN has UDMA and TEGDMA monomers in their composition. Great water sorption has been reported in composites containing high TEGDMA content compared to other methacrylate monomers ${ }^{23}$. This is explained by the hydrophilicity of TEGDMA. In this sense, hydrophilic monomers facilitate pigment infiltrations leading to easier discoloration.

On the other hand, feldspathic ceramics consist of a vitreous matrix filled with silicon oxide and leucite crystals. Since glasses do not suffer water sorption as polymers, glass-ceramics are more resistant to discoloration than resin composites. To date, the manufacturer of Brava block does not disclose the main methacrylate monomers in the materials' composition. However, it is well known that resin composites are more color unstable than dental ceramics $8,15,24$. PICN has only $14 \mathrm{w} \%$ of UDMA and TEGDMA in its composition. Still, this amount of composite was sufficient to decrease its color stability when compared to a feldspathic ceramic. A previous study proposed a new classification for ceramic and ceramic-like materials ${ }^{25}$. They classified polymer-matrices containing predominantly inorganic refractory compounds as resin-matrix ceramics. In this sense, Vita Enamic and Brava block would be included in the same category, which also corroborates the similarity observed in our results.

In contrast to our results, previous studies have found the highest discolorations in resin composites, followed by PICN, and glass ceramics, which reach the lowest values after staining in red wine ${ }^{9,26}$. Nonetheless, these studies used the CIELAB formula for color difference calculations and days straight of immersion in the beverages. One should note that the CIEDE2000 formula is a more sophisticated tool which better represents the color differences perceived by the human eye than $C I E L A B^{27,28}$. Therefore, despite conflicting with previously published results, using CIEDE2000 for color and translucency calculations might bring more accuracy to the results of the present study.

According to the values obtained, the initial translucency of PICN would be lower than FEL and RC (Table 4). However, the CAD/CAM blocks used in this study are available in different color scales so that comparisons among the materials' translucency would be biased. Therefore, we evaluated the translucency stability of each material throughout the 30-day staining separately to avoid unfair comparisons. Our results showed that all the materials maintained their translucency values over the staining process. Previous studies have observed changes in translucency of PICN after being subjected to red wine $^{13,14}$. Nevertheless, these studies were obtained from days straight of immersion 
in red wine, which might have overestimated the results. Authors that implemented staining protocols similar to the one used in the present study found no differences in the translucency of glass-ceramics or resin composites ${ }^{8}$.

Previous studies have observed that surface finishing methods can increase roughness and consequently decrease the translucency ${ }^{29}$, or lead to color alteration of restorative materials $^{8,30}$. Different finishing approaches were performed in our study, since the FEL samples received a glaze layer and the $\mathrm{RC}$ and PICN samples were polished with Sof-Lex discs. This polishing sequence was chosen since diamond discs are frequently used in daily dental practice. Furthermore, the diamond disc sequence is suggested by the manufacturers for repair, pre-polishing, and/or polishing of PICN and $\mathrm{RC}^{31,32}$. Even at the risk of influencing the results due to the different surfaces, it was decided to reproduce finishing procedures closer to the clinical conditions. On the other hand, the initial roughness was proven to be similar among the experimental groups (Table 2). This evidences standardization of the samples regarding the surfaces subjected to the staining process.

The described results are somehow clinically applicable to patients who have a pigment-rich diet. We employed a 30-min immersion in red wine twice a day with $12 \mathrm{~h}$ of dwell time. The staining protocol is plausible since the aforementioned patients might keep their restorations in contact with pigments for this amount of time a day. Brushing is an important clinical factor and it was proven to reduce staining in resin composites ${ }^{33}$ and to cause color alteration in glass-ceramics ${ }^{34}$. Nonetheless, brushing was not included in our study design. Even so, our findings indicate that polished PICN tends to behave as a composite regarding color stability when in contact with highly pigment beverages. Moreover, PICN has shown mechanical properties superior to composites ${ }^{35,36}$, which must also be considered when choosing the best restorative material for each clinical scenario.

\section{Conclusion}

PICN was not as color stable as the feldspathic ceramic at the end of the study. Its color alteration was comparable to the resin composite when subjected to contact with red wine. All tested CAD/CAM materials reached the unacceptable threshold of discoloration already at 15 days of staining. However, the translucency of all restorative materials was stable throughout the 30-day staining protocol.

\section{Acknowledgments}

The authors are thankful to the Federal Agency for Support and Evaluation of Graduate Education (CAPES) (finance code 001) for Master and Ph.D. scholarships.

Conflicts of interest: none

\section{References}

1. Stawarczyk B, Sener B, Trottmann A, Roos M, Ozcan M, Hammerle CHF. Discoloration of manually fabricated resins and industrially fabricated CAD/CAM blocks versus glass-ceramic: effect of storage media, duration, and subsequent polishing. Dent Mater J. 2012 May;31(3):377-83 doi: 10.4012/dmj.2011-238. 
2. Albero A, Pascual A, Camps I, Grau-Benitez M. Comparative characterization of a novel cad-cam polymer-infiltrated-ceramic-network. J Clin Exp Dent. 2015 Oct; 7(4):e495-500. doi: $10.4317 /$ jced.52521.

3. Vanoorbeek S, Vandamme K, Lijnen I, Naert I. Computer-aided designed/computer-assisted manufactured composite resin versus ceramic single-tooth restorations: a 3-year clinical study. Int J Prosthodont. 2010 May-Jun;23(3):223-30.

4. Borba M, de Araujo MD, Fukushima KA, Yoshimura HN, Cesar PF, Griggs JA, et al. Effect of the microstructure on the lifetime of dental ceramics. Dent Mater. 2011 Jul;27(7):710-21. doi: 10.1016/j.dental.2011.04.003

5. Gonzaga CC, Yoshimura HN, Cesar PF, Miranda WG. Subcritical crack growth in porcelains, glass-ceramics, and glass-infiltrated alumina composite for dental restorations. J Mater Sci Mater Med. 2009 May;20(5):1017-24. doi: 10.1007/s10856-008-3667-z.

6. Venturini AB, Prochnow C, Pereira GKR, Segala RD, Kleverlaan CJ, Valandro LF. Fatigue performance of adhesively cemented glass-, hybrid- and resin-ceramic materials for CAD/CAM monolithic restorations. Dent Mater. 2019 Apr;35(4):534-42. doi: 10.1016/j.dental.2019.01.013.

7. Vita Enamic - Technical and scientific documentation. Bad Sackingen: Vita Zahnfabrik. [cited 2021 Mar 10]. Available from: https://cdn.vivarep.com/contrib/vivarep/media/pdf/4_4642_ ENAMICTechnicalandScientific_20170830205744578.pdf.

8. Dellazzana FZ, Rodrigues CS, Mallmann A, Jacques LB. Optical Properties of a Glass Ceramic and an Indirect Resin Composite: Effects of Polishing and Staining. J Health Sci. 2019 Dec;21(5):6. doi: https://doi.org/10.17921/2447-8938.2019v21n5p512-517.

9. Stawarczyk B, Liebermann A, Eichberger M, Guth JF. Evaluation of mechanical and optical behavior of current esthetic dental restorative CAD/CAM composites. J Mech Behav Biomed Mater. 2015 Mar;55:1-11. doi: 10.1016/j.jmbbm.2015.10.004.

10. Ardu S, Braut V, Gutemberg D, Krejci I, Dietschi D, Feilzer AJ. A long-term laboratory test on staining susceptibility of esthetic composite resin materials. Quintessence Int. 2010 Sep;41(8):695-702.

11. Bagheri R, Burrow MF, Tyas M. Influence of food-simulating solutions and surface finish on susceptibility to staining of aesthetic restorative materials. J Dent. 2005 May;33(5):389-98. doi: 10.1016/j.jdent.2004.10.018

12. Kelly JR. Dental ceramics: what is this stuff anyway? J Am Dent Assoc. 2008 Sep;139 Suppl:4S-7S. doi: 10.14219/jada.archive.2008.0359.

13. Barutcugil C, Bilgili D, Barutcigil K, Dündar A, Büyükkaplan US, Yilmaz B. Discoloration and translucency changes of CAD-CAM materials after exposure to beverages. J Prosthet Dent. 2019 Sep;122(3):325-31. doi: 10.1016/j.prosdent.2019.01.009.

14. Quek SHQ, Yap AUJ, Rosa V, Tan KBC, Teoh KH. Effect of staining beverages on color and translucency of CAD/CAM composites. J Esthet Restor Dent. 2018 Mar;30(2):E9-E17. doi: $10.1111 /$ jerd. 12359

15. Seyidaliyeva A, Rues S, Evagorou Z, Hassel AJ, Rammelsberg P, Zenthöfer A. Color stability of polymer-infiltrated-ceramics compared with lithium disilicate ceramics and composite. J Esthet Restor Dent. 2020 Jan;32(1):43-50. doi: 10.1111/jerd.12525.

16. Sulaiman TA, Suliman AA, Mohamed EA, Rodgers B, Altak A, Johnston WM. Optical properties of bisacryl-, composite-, ceramic- resin restorative materials: an aging simulation study. J Esthet Restor Dent. 2021 Sep;33(6):913-8. doi: 10.1111/jerd.12653.

17. Paravina RD, Ghinea R, Herrera LJ, Bona AD, Igiel C, Linninger M, et al. Color difference thresholds in dentistry. J Esthet Restor Dent. 2015 Mar-Apr;27 Suppl 1:S1-9. doi: 10.1111/jerd.12149.

18. Salas M, Lucena C, Herrera LJ, Yebra A, Della Bona A, Pérez MM. Translucency thresholds for dental materials. Dent Mater. 2018 Aug;34(8):1168-74. doi: 10.1016/j.dental.2018.05.001. 
19. Demarco FF, Collares K, Coelho-de-Souza FH, Correa MB, Cenci MS, Moraes RR, et al. Anterior composite restorations: A systematic review on long-term survival and reasons for failure. Dent Mater. 2015 Oct;31(10):1214-24. doi: 10.1016/j.dental.2015.07.005.

20. Morimoto S, Albanesi RB, Sesma N, Agra CM, Braga MM. Main Clinical Outcomes of feldspathic porcelain and glass-ceramic laminate veneers: a systematic review and meta-analysis of survival and complication rates. Int J Prosthodont. 2016 Jan-Feb;29(1):38-49. doi: $10.11607 /$ ijp. 4315

21. Chirumamilla G, Goldstein CE, Lawson NC. A 2-year Retrospective Clinical study of Enamic Crowns Performed in a Private Practice Setting. J Esthet Restor Dent. 2016 Jul;28(4):231-7. doi: $10.1111 /$ jerd. 12206 .

22. Spitznagel FA, Scholz KJ, Vach K, Gierthmuehlen PC. Monolithic polymer-infiltrated ceramic network cad/cam single crowns: three-year mid-term results of a prospective clinical study. Int J Prosthodont. 2020 Mar-Apr;33(2):160-8. doi: 10.11607/ijp.6548.

23. Gusmao GM, De Queiroz TV, Pompeu GF, Menezes Filho PF, da Silva CH. The influence of storage time and $\mathrm{pH}$ variation on water sorption by different composite resins. Indian J Dent Res 2013 Jan-Feb;24(1):60-5. doi: 10.4103/0970-9290.114954.

24. Choi YS, Kang KH, Att W. Evaluation of the response of esthetic restorative materials to ultraviolet aging. J Prosthet Dent. 2020 Oct 8;S0022-3913(20)30471-6. doi: 10.1016/j.prosdent.2020.09.007.

25. Gracis S, Thompson VP, Ferencz JL, Silva NR, Bonfante EA. A new classification system for all-ceramic and ceramic-like restorative materials. Int J Prosthodont. 2015 May-Jun;28(3):227-35. doi: $10.11607 /$ ijp.4244.

26. Alharbi A, Ardu S, Bortolotto T, Krejci I. Stain susceptibility of composite and ceramic CAD/ CAM blocks versus direct resin composites with different resinous matrices. Odontology 2017 Apr;105(2):162-9. doi: 10.1007/s10266-016-0258-1.

27. Gomez-Polo C, Portillo Munoz M, Lorenzo Luengo MC, Vicente P, Galindo P, Casado AMM. Comparison of two color-difference formulas using the Bland-Altman approach based on natural tooth color space. J Prosthet Dent. 2016 Apr;1 15(4):482-8. doi: 10.1016/j.prosdent.2015.07.013.

28. Ren J, Lin H, Huang Q, Zheng G. Determining color difference thresholds in denture base acrylic resin. J Prosthet Dent. 2015 Nov;114(5):702-8. doi: 10.1016/j.prosdent.2015.06.009

29. Akar GC, Pekkan G, Cal E, Eskitascioglu G, Ozcan M. Effects of surface-finishing protocols on the roughness, color change, and translucency of different ceramic systems. J Prosthet Dent. 2014 Aug;112(2):314-21. doi: 10.1016/j.prosdent.2013.09.033.

30. Kanat-Erturk B. Color Stability of CAD/CAM Ceramics prepared with different surface finishing procedures. J Prosthodont. 2020 Feb;29(2):166-72. doi: 10.1111/jopr.13019.

31. Vita Enamic - Working Instructions. Bad Sackingen: Vita Zahnfabrik. [cited 2021 Mar 10] Available from: http://data.dt-shop.com/fileadmin/media/ga/1034_ga_enu.pdf.

32. FGM Dental Group. Perfil técnico Brava block. Joinvile: FGM Dental Group; 2019 Feb 1 [cited 2021 Mar 10]. Available from: https://issuu.com/fgmprodutosodontologicos/docs/perfil_brava-block.

33. Mozzaquatro LR, Rodrigues CS, Kaizer MR, Lago M, Mallmann A, Jacques LB. The effect of brushing and aging on the staining and smoothness of resin composites. J Esthet Restor Dent. 2017 Apr;29(2):E44-E55. doi: 10.1111/jerd.12293.

34. Yuan JC, Barao VAR, Wee AG, Alfaro MF, Afshari FS, Sukotjo C. Effect of brushing and thermocycling on the shade and surface roughness of CAD-CAM ceramic restorations. J Prosthet Dent. 2018 Jun;119(6):1000-6. doi: 10.1016/j.prosdent.2017.06.001. 
35. Porto TS, Roperto RC, Akkus A, Akkus O, Teich S, Faddoul F, et al. Effect of storage and aging conditions on the flexural strength and flexural modulus of CAD/CAM materials. Dent Mater J. 2019 Mar;38(2):264-70. doi: 10.4012/dmj.2018-111.

36. Facenda JC, Borba M, Benetti P, Della Bona A, Corazza PH. Effect of supporting substrate on the failure behavior of a polymer-infiltrated ceramic network material. J Prosthet Dent. 2019 Jun;121(6):929-34. doi: 10.1016/j.prosdent.2018.08.008. 